\title{
Cardiovascular morbidity and the use of inhaled bronchodilators
}

\author{
Christine Macie \\ Kate Wooldrage \\ Jure Manfreda \\ Nicholas Anthonisen \\ Department of Medicine, University \\ of Manitoba, Winnipeg, Manitoba, \\ Canada
}

\begin{abstract}
We used the Manitoba Health database to examine the relationship between use of inhaled respiratory drugs in people with chronic obstructive respiratory diseases and cardiovascular hospitalizations from 1996 through 2000. The drugs examined were beta agonists [BA], ipratropium bromide IB, and inhaled steroids (ICS). End points were first hospitalizations for supraventricular tachycardia, myocardial infarction, heart failure or stroke. A nested case control analysis was employed comparing people with and without cardiovascular events. Cases and controls were matched for gender and age, and conditional logistic regression was used in multivariate analysis considering other respiratory drugs, respiratory diagnosis and visit frequency, non-respiratory, non-cardiac comorbidities, and receipt of drugs for cardiovascular disease.

In univariate analyses, BA, IB and ICS were all associated with hospitalizations for cardiovascular disease, but in multivariate analyses ICS did not increase risk while both BA and IB did. There were interactions between respiratory and cardiac drugs receipt in that bronchodilator associated risks were higher in people not taking cardiac drugs; this was especially true for stroke. There were strong interactions with specific cardiac drugs; for example, both BA and IB substantially increased the risk of supraventricular tachycardia in patients not anti-arryhthmic agents, but not in the presence of such agents.

We conclude that bronchodilator therapy for chronic obstructive diseases is associated with increased cardiovascular risk, especially in patients without previous cardiovascular diagnoses, and that this is unlikely due to the severity of the respiratory disease, since risk was not increased with ICS.
\end{abstract}

Keywords: bronchodilator therapy, inhaled corticosteroids, nested case control study

Bronchodilators are widely used and effective drugs for the treatment of obstructive lung diseases. However, concerns have been raised about possible associations of these drugs with cardiovascular morbidity and mortality. Most reports have implicated inhaled beta agonists (BA), especially in patients with preexisting cardiac disease (Coughlin et al 1995; Au et al 2002, 2003, 2004; Salpeter et al 2004), but other studies have not found an association between these agents and cardiovascular outcomes (Suissa et al 1994, 1996, 2003). The other widely used bronchodilator, the anticholinergic ipratropium bromide (IB), has been less extensively studied in this regard. A large clinical trial involving IB in patients with mild COPD found a trend toward increased cardiovascular mortality and supraventricular tachycardias requiring hospitalization among participants assigned to IB as opposed to placebo (Anthonisen et al 2002). An association between IB and mortality had been noted previously in asthmatics (Guite et al 1999), but may have been confounded, since IB is more commonly used in COPD, and the two diseases are often confused. A retrospective cohort study also found IB use associated with increased mortality in both COPD and asthma (Ringbaek and Viskum 2003), but a large database study did not (Sin and Tu 2000). 
It is well known that COPD patients have an increased risk of death from cardiovascular disease related to their smoking history and reduced lung function (Sin and Mann 2003; Sin et al 2005). There is also substantial prevalence of asymptomatic supraventricular and ventricular arrhythmias in people with severe COPD (Hudson et al 1973; Kleiger and Senior 1974). It is therefore conceivable that inhaled beta agonists or anti-cholinergics such as IB could cause arrhythmias and cardiovascular events in COPD patients. We have explored this possibility.

\section{Methods}

\section{Data source}

The Province of Manitoba provides universal health care insurance for all its residents (approximately 1.1 million). For research purposes, the Manitoba Population Health Research Repository integrates anonymous records of all inpatient and outpatient physician contacts, vital statistics (date and cause of death) and prescription records. In addition, it is linked via an anonymous identifier to the Population Registry, which indicates the duration of health insurance coverage for each permanent Manitoba resident, coverage ending with leaving the province or with death. Physicians are remunerated on the basis of claims for payment describing services provided and the diagnosis for which services were rendered. The Drug Programs Information Network (DPIN) database is created by provincial retail pharmacies entering prescriptions in real time in order to facilitate screening for inappropriate use, such as drug interactions, and co-payment for medication. The pharmaceutical database contains the individual anonymous identifier, as well as the information about the drug dispensed: the anatomical therapeutic chemical (ATC) code, drug identification number (DIN), date, quantity dispensed, and the number of days covered by the medication supplied (WHO 1995).

\section{Subjects}

We identified all people over 35 years of age who, between January 1, 1996 and December 31, 2000, had a physician contact for bronchitis (ICD-9 code 490) asthma (ICD-9 code 493) or COPD (ICD-9 codes 490, 491, 492, and 496) (WHO 1978). Subjects were permanent residents of the province on January 1, 1996 or at first physician contact after that date and were observed until leaving the province, death or December 31, 2000.

\section{Variables}

The outcome was the first hospitalization between January 1, 1996, and December 31, 2000, for selected cardiovascular events: supra-ventricular tachycardia (SVT) (ICD-9 427.0, 427.31, 427.32, 427.61), myocardial infarction (MI) (ICD-9 410), heart failure (HF) (ICD-9 428), and stroke (ICD-9 430-438).

Patients were classified according to sex, age, and respiratory diagnostic group: asthma, COPD, both asthma and COPD, and bronchitis. Patients in the first three groups could also have visits for bronchitis. Three groups of respiratory drugs were examined: inhaled beta agonists (BA), inhaled anti-cholinergics (IB), and inhaled corticosteroids (ICS). We recorded physician visits for respiratory diagnoses and for non-cardiac co-morbidities, and to assess cardiac co-morbidities we noted recipients of cardiac drugs. Non-cardiac comorbidities were derived from physician claims for paralysis (ICD-9 342-344), diabetes (ICD-9 250), renal failure (ICD-9 403, 404, 582, 583, 585, 586, 588), liver disease (ICD-9 070 , $456,571,572$ ), peptic ulcer (ICD-9 531-534), malignancy (ICD-9 200-203, 238, 273), collagen vascular disease (ICD-9 701, 710, 714, 720, 725) and dementia (ICD-9 290, 797). In assessing cardiac co-morbidities, cardiac medications were classified into 8 categories: anti-arrhythmics (excluding beta-blockers), nitrates, furosemide, beta-blockers, calcium channel blockers, angiotensin converting enzyme inhibitors (ACEI), other anti-hypertensives, and cholesterol lowering agents. To assess co-morbidities, anti-arrhythmics were excluded from the analyses of SVT.

\section{Design}

We performed a nested case-control analyses with the first hospitalization for a specified cardiovascular event defining the case. The date of hospitalization of the case defined the index date. Each case was matched according to sex, age and duration of insurance coverage with up to ten control subjects that did not have that event prior to the index date. The control subjects were selected randomly if more than ten were available for a case. Respiratory drug exposure was analyzed according to receipt of one of the three types of drugs 60 days or 365 days prior to the event; it should be noted that those exposed within 365 days included those exposed within 60 days. Cardiac drug exposure was defined by receiving cardiac drugs within 365 days prior to the index date.

\section{Analysis}

Conditional logistic regression was used. Odds ratios (OR) and confidence intervals $(95 \% \mathrm{CI})$ were calculated and results were considered statistically significant if $p<0.05$. Analyses were conducted using SAS software, version 8.2 (SAS Institute, Inc., Cary, North Carolina). Univariate models assessed 
the association of each drug group and exposure with each outcome. In multivariate models, we successively added other respiratory drugs, respiratory diagnostic group, number of physician visits for respiratory diagnoses, non-cardiac co-morbidities, and cardiac drugs.

We also tested for interactions between cardiac drugs, taken as a whole, and respiratory drugs for each of the outcomes and looked for interactions with specific cardiac medications as follows: SVT (antiarrhythmics), MI (all except antiarrhythmics), HF (all except anticholesterol agents) and stroke (all cardiac drugs).

The Ethics Board of the University of Manitoba and the Health Information Privacy Committee of Manitoba Health approved the study.

\section{Results}

A total of 222,272 of Manitoba residents with a respiratory diagnosis were enumerated during 5 years ending on December 31, 2000. Characteristics of cases and controls are shown in Table 1 by cardio-vascular diagnosis at the time of the first hospitalization. The proportion of males was the highest (61.7\%) among those hospitalized for myocardial infarction while those hospitalized for HF were the oldest (76.0 years). A relatively small proportion of cases received respiratory drugs during the year prior to the hospitalization, the highest being people with HF: about one third received BA. Use of BA and IB was more common in cases than controls. Also, ICS use was more common in cases, except for those with stroke. With respect to respiratory morbidity, cases and controls were well balanced for SVT, MI and stroke. For HF, a greater proportion had a history of COPD. As expected, use of cardiac drugs was substantially greater among cases than among controls. Non-cardiac co-morbidities were also more common in cases than in controls.

Tables 2-5 show univariate and multivariate associations between respiratory drugs and cardiovascular hospitalizations. The likelihood of a hospitalization for SVT, MI, and HF was significantly increased for those to whom BA, IB, or ICS were dispensed within 60 days or one year prior to the hospitalization. The association was weaker for those hospitalized because of a stroke. When all three categories of respiratory drugs were fit into the multiple logistic regression model simultaneously, the ORs diminished for each respiratory drug and all outcomes. However, they remained significantly increased for BA and IB. The ORs associated with ICS became not significant or even significantly protective (ICS within 60 days for SVT, HF, and stroke, and 365 days for HF and stroke). Addition of respiratory diagnoses and visit frequency to the model did not further affect the ORs. Similarly, the addition of non-respiratory, non-cardio-vascular co-morbidity to the model did not have an effect on the ORs.

There were significant interactions between cardiac drugs (as a group) and the bronchodilators, also shown in Tables $2-5$. The use of cardiac drugs decreased the likelihood of hospitalization associated with IB and BA (for SVT and stroke) and BA (for stroke). IB and BA increased the risk of stroke in people not taking cardiac drugs, but not when they were taking them.

Table 6 shows the effects of specific cardiac drugs on the risk of hospitalization associated with bronchodilators. Anti-arrhythmics were not included in the initial tests for interaction with SVT because their use closely coincided with the diagnosis. They abolished the increased risk for SVT with both bronchodilators at both time points. Furosemide reduced but did not eliminate the increased risk of heart failure with both bronchodilators at both time points, as did angiotensin inhibitors in the case of beta agonists. Patients not on angiotensin inhibitors had an increased risk of stroke with IB, as was the case with patients not on anti-hypertensives who used beta agonists.

\section{Discussion}

Our finding that BA use was associated with cardiovascular morbidity was consistent with others in the literature (Coughlin et al 1995; Au et al 2002, 2003, 2004; Salpeter et al 2004), and with the pharmacology of these drugs (Robin and McCauley 1992; Iskander et al 2004; Kallergis et al 2005). Suissa et al have failed to find such associations but one of their studies (Suissa et al 1996) noted that nebulized or orally administered BA were associated with cardiac deaths, and another (Suissa et al 1994) was confined to asthmatics, who are less likely to have cardiovascular events than people with COPD.

We also found that IB use was associated with cardiovascular events to more or less the same extent as BA. This was not entirely unprecedented; a large clinical trial comparing IB with placebo in mild COPD noted increased cardiovascular morbidity and mortality of borderline significance in the group assigned IB, and a particularly suggestive increase in the incidence of SVT (Anthonisen et al 2002). This was consistent with the vagolytic nature of the drug if it was absorbed (Coleman et al 1975), and arrhythmias appear to be the most credible mechanism for IB to cause cardiovascular events. Other studies associating IB with excess mortality (Guite et al 1999; Rigbaek and Viskum 2003) suffered from potential confounders in that IB use was associated with 
Table I Characteristics of cases (at first hospitalization) and controls

\begin{tabular}{|c|c|c|c|c|c|c|c|c|c|}
\hline & & $\begin{array}{l}\text { SVT } \\
\text { cases }\end{array}$ & Controls & $\begin{array}{l}\text { MI } \\
\text { cases }\end{array}$ & Controls & $\begin{array}{l}\text { HF } \\
\text { cases }\end{array}$ & Controls & $\begin{array}{l}\text { Stroke } \\
\text { cases }\end{array}$ & Controls \\
\hline \multicolumn{2}{|c|}{ Number of subjects } & 2054 & 20501 & 3855 & 38490 & 5407 & 53929 & 4961 & 49487 \\
\hline Gender & Males & 48.2 & & 61.7 & & 49.8 & & 49.8 & \\
\hline \multirow[t]{2}{*}{ Age } & mean & 71.2 & & 69.1 & & 76.0 & & 73.4 & \\
\hline & 25th , 75th percentile & 64,80 & & 61,79 & & 70,84 & & 67,82 & \\
\hline \multicolumn{10}{|c|}{ Respiratory Co-morbidity } \\
\hline & Asthma & 10.1 & 10.9 & 9.6 & 11.0 & 7.1 & 9.1 & 8.0 & 10.0 \\
\hline & COPD & 27.1 & 26.3 & 29.5 & 25.6 & 41.7 & 28.9 & 31.5 & 27.9 \\
\hline & Asthma and COPD & 10.5 & 9.1 & 10.8 & 9.5 & 13.3 & 10.1 & 9.4 & 10.0 \\
\hline & Bronchitis & 52.3 & 53.7 & 50.1 & 53.9 & 37.9 & 52.1 & 51.1 & 52.2 \\
\hline Any Non & ac Co-morbidity & 39.5 & 34.0 & 44.4 & 32.9 & 51.7 & 35.8 & 46.2 & 34.9 \\
\hline \multicolumn{10}{|c|}{ Drug dispensed within } \\
\hline & IB 60 Days & 7.8 & 4.8 & 6.6 & 4.7 & 14.9 & 5.4 & 5.6 & 5.0 \\
\hline & I Year & 11.2 & 7.6 & 10.3 & 7.5 & 20.4 & 8.4 & 10.1 & 7.9 \\
\hline & BA 60 Days & 13.2 & 9.3 & 13.1 & 9.4 & 24.4 & 10.1 & 10.5 & 9.8 \\
\hline & I Year & 22.4 & 17.2 & 21.1 & 16.8 & 34.3 & 17.6 & 19.3 & 17.4 \\
\hline & ICS 60 Days & 7.2 & 6.4 & 7.9 & 6.2 & 12.0 & 6.9 & 6.1 & 6.7 \\
\hline & I Year & 13.5 & 11.3 & 14.0 & 11.6 & 18.7 & 12.0 & 11.6 & 11.7 \\
\hline \multicolumn{10}{|c|}{ Cardiac Drugs } \\
\hline & Antiarrhythmics & 36.8 & 9.2 & 11.8 & 7.9 & 34.6 & 9.8 & 16.8 & 9.6 \\
\hline & Nitrates & 31.0 & 16.1 & 30.1 & 13.7 & 40.7 & 16.6 & 25.0 & 16.4 \\
\hline & Antihypertensives & 37.5 & 27.6 & 32.4 & 25.7 & 42.0 & 28.8 & 37.8 & 28.1 \\
\hline & Furosemide & 33.9 & 17.3 & 23.8 & 14.5 & 65.0 & 18.8 & 27.8 & 18.2 \\
\hline & Betablockers & 29.4 & 14.1 & 20.1 & 12.8 & 20.7 & 13.8 & 20.4 & 13.8 \\
\hline & Calcium Channel Blockers & 16.5 & 7.6 & 12.4 & 6.6 & 15.2 & 7.7 & 11.3 & 7.4 \\
\hline & ACEI & 37.1 & 21.9 & 30.2 & 20.5 & 52.4 & 21.6 & 34.9 & 21.9 \\
\hline & Anticholesterol & 13.0 & 10.5 & 15.1 & 10.2 & 12.1 & 9.2 & 13.8 & 9.4 \\
\hline & Any & 81.2 & 55.3 & 67.4 & 51.6 & 88.9 & 58.6 & 73.2 & 56.7 \\
\hline
\end{tabular}

disease severity and/or the diagnosis of COPD as opposed to asthma. Using a very large database, Sin and Tu (2000) did not find and association between IB and mortality in COPD patients after adjustment for potential confounders.
The strength of any conclusions in regard to our data depends on the validity of our approach. Our database is inclusive and detailed. It included all residents of Manitoba: approximately 1.1 million people. We were able to enumerate

Table 2 Odds ratios for the first hospitalization due to SVT

\begin{tabular}{|c|c|c|c|c|c|c|c|c|c|}
\hline & & & \multicolumn{2}{|l|}{ Univariate } & \multicolumn{5}{|l|}{ Multivariate } \\
\hline & & & $\begin{array}{l}\text { All } \\
\text { respiratory } \\
\text { drugs }\end{array}$ & $\begin{array}{l}\text { Plus } \\
\text { respiratory } \\
\text { comorbidity }\end{array}$ & $\begin{array}{l}\text { Plus } \\
\text { other } \\
\text { comorbidity }\end{array}$ & $\begin{array}{l}\text { Plus } \\
\text { cardiac } \\
\text { drugs }\end{array}$ & $\begin{array}{l}\text { Interaction } \\
\text { with cardiac } \\
\text { drugs } \\
\text { p-value }\end{array}$ & $\begin{array}{l}\text { No cardiac } \\
\text { drugs }\end{array}$ & $\begin{array}{l}\text { Cardiac } \\
\text { drugs }\end{array}$ \\
\hline \multirow[t]{6}{*}{60 Days } & IB & 1.68 & 1.48 & 1.49 & 1.49 & 1.38 & 0.011 & 2.38 & 1.24 \\
\hline & & $1.41,2.00$ & I.19, I.84 & $1.20,1.86$ & $1.20,1.85$ & I.10, I.72 & & I.5I, 3.74 & $0.99,1.55$ \\
\hline & BA & $\mathrm{I} .48$ & 1.40 & 1.40 & 1.37 & 1.31 & $>0.05$ & & \\
\hline & & $1.29,1.70$ & I. $17,1.67$ & $1.16,1.69$ & I.I4, I.64 & I.09, I.57 & & & \\
\hline & CS & 1.13 & 0.79 & 0.79 & 0.80 & 0.79 & $>0.05$ & & \\
\hline & & $0.95,1.35$ & $0.64,0.98$ & $0.64,0.98$ & $0.65,0.99$ & $0.64,0.99$ & & & \\
\hline \multirow[t]{6}{*}{ I year } & IB & 1.53 & 1.33 & 1.36 & 1.36 & 1.27 & 0.046 & 1.80 & 1.17 \\
\hline & & I.32, I.77 & I.12, I.59 & $1.13,1.63$ & $1.13,1.63$ & $1.06,1.53$ & & $1.22,2.65$ & $0.97,1.41$ \\
\hline & BA & 1.40 & 1.32 & 1.35 & 1.32 & 1.25 & $>0.05$ & & \\
\hline & & $1.25,1.56$ & $1.14,1.53$ & $1.16,1.57$ & $1.14,1.54$ & $1.07,1.46$ & & & \\
\hline & CS & 1.23 & 0.93 & 0.96 & 0.96 & 0.93 & $>0.05$ & & \\
\hline & & I.07, I.40 & $0.78,1.09$ & $0.80,1.14$ & $0.80,1.14$ & $0.78, I . I I$ & & & \\
\hline
\end{tabular}


Table 3 Odds ratios for first hospitalization due to myocardial infarction

\begin{tabular}{|c|c|c|c|c|c|c|c|}
\hline & & & \multicolumn{2}{|l|}{ Univariate } & \multicolumn{3}{|l|}{ Multivariate } \\
\hline & & & $\begin{array}{l}\text { All } \\
\text { respiratory } \\
\text { drugs }\end{array}$ & $\begin{array}{l}\text { Plus } \\
\text { respiratory } \\
\text { comorbidity }\end{array}$ & $\begin{array}{l}\text { Plus } \\
\text { other } \\
\text { comorbidity }\end{array}$ & $\begin{array}{l}\text { Plus } \\
\text { cardiac } \\
\text { drugs }\end{array}$ & $\begin{array}{l}\text { Interaction } \\
\text { with cardiac } \\
\text { drugs } \\
\text { p-value }\end{array}$ \\
\hline \multirow[t]{6}{*}{60 Days } & IB & 1.42 & 1.13 & 1.05 & 1.04 & 1.00 & $>0.05$ \\
\hline & & $1.24,1.63$ & $0.96,1.33$ & $0.89,1.23$ & $0.88,1.23$ & $0.85,1.18$ & \\
\hline & BA & 1.46 & 1.39 & 1.35 & 1.33 & 1.31 & $>0.05$ \\
\hline & & $1.32,1.61$ & $1.22,1.59$ & I. $18,1.55$ & $1.16,1.53$ & I.15, I.5। & \\
\hline & CS & 1.30 & 1.01 & 1.01 & 1.04 & 0.99 & $>0.05$ \\
\hline & & I.15, I.48 & $0.87,1.17$ & $0.87,1.18$ & $0.89,1.22$ & $0.85,1.16$ & \\
\hline \multirow[t]{6}{*}{ I year } & IB & 1.40 & 1.22 & 1.13 & I.II & 1.07 & $>0.05$ \\
\hline & & $1.25,1.57$ & $1.07,1.39$ & $0.98,1.29$ & $0.97,1.28$ & $0.93,1.23$ & \\
\hline & BA & 1.33 & 1.24 & 1.22 & 1.18 & 1.15 & $>0.05$ \\
\hline & & I.22, I.44 & $1.11,1.39$ & $1.08,1.36$ & $1.05,1.32$ & $1.02,1.29$ & \\
\hline & CS & 1.24 & 1.00 & 1.02 & 1.04 & 1.01 & $>0.05$ \\
\hline & & $1.13,1.37$ & $0.89,1.13$ & $0.89,1.16$ & $0.91,1.18$ & $0.89,1.15$ & \\
\hline
\end{tabular}

claims for hospitalization, physician visits and all respiratory medications received by each subject with bronchitis, COPD or asthma. We attempted to control for disease severity and for cardiac and non-cardiac co-morbidities. As with all database studies, this had several important weaknesses. We cannot be certain of the accuracy of the diagnoses we were concerned with, though the accuracy of diagnosis of ischemic heart disease and COPD has been reported from a similar database (Curkendall et al 2006); agreement between databases and survey results is at best "moderate" in chronic diseases such as asthma (Huzel et al 2002). In the absence of laboratory data, we used proxies such as other drugs and physician visits to assess severity. We equated drug use with drug dispensing, and did not know whether patients actually used the medications that they received, though drug effects were most prominent in the 60 days after drug prescriptions, when it was reasonable to assume that the drugs were actually used. Although we adjusted for co-morbidities, such adjustments are approximations. We limited our analyses to first hospitalization for a cardiovascular diagnosis, thereby avoiding the weakness that pharmacy-derived drug databases do not enumerate drugs administered to hospitalized patients.

An alternative explanation for our results would be that bronchodilator use reflected severity of obstructive lung disease in a way that was not captured by our other measurements such as physician visits. There is excellent evidence

Table 4 Odds ratios for first hospitalization due to heart failure

\begin{tabular}{|c|c|c|c|c|c|c|c|}
\hline & & & \multicolumn{2}{|l|}{ Univariate } & \multicolumn{3}{|l|}{ Multivariate } \\
\hline & & & $\begin{array}{l}\text { All } \\
\text { respiratory } \\
\text { drugs }\end{array}$ & $\begin{array}{l}\text { Plus } \\
\text { respiratory } \\
\text { comorbidity }\end{array}$ & $\begin{array}{l}\text { Plus } \\
\text { other } \\
\text { comorbidity }\end{array}$ & $\begin{array}{l}\text { Plus } \\
\text { cardiac } \\
\text { drugs }\end{array}$ & $\begin{array}{l}\text { Interaction } \\
\text { with cardiac } \\
\text { drugs } \\
\text { p-value }\end{array}$ \\
\hline \multirow[t]{6}{*}{60 Days } & IB & 3.07 & 1.80 & 1.59 & 1.59 & 1.47 & $>0.05$ \\
\hline & & $2.82,3.34$ & $1.62,2.00$ & $1.43,1.77$ & I.62, I.78 & I.3I, I.64 & \\
\hline & BA & 2.88 & 2.45 & 2.25 & 2.21 & 1.99 & $>0.05$ \\
\hline & & $2.69,3.08$ & $2.23,2.68$ & $2.04,2.47$ & $2.00,2.43$ & $\mathrm{I} .8 \mathrm{I}, 2.20$ & \\
\hline & CS & 1.84 & 0.82 & 0.83 & 0.87 & 0.85 & $>0.05$ \\
\hline & & $1.69,2.02$ & $0.73,0.91$ & $0.74,0.92$ & $0.78,0.97$ & $0.76,0.95$ & \\
\hline \multirow[t]{6}{*}{ I year } & IB & 2.80 & 1.90 & 1.69 & 1.68 & 1.55 & $>0.05$ \\
\hline & & $2.60,3.01$ & I.73, 2.08 & $1.54,1.86$ & I.53, I.85 & I.4I, I.7I & \\
\hline & BA & 2.45 & 2.15 & 2.03 & 1.96 & $\mathrm{I} .74$ & $>0.05$ \\
\hline & & $2.3 \mathrm{I}, 2.6 \mathrm{I}$ & $1.98,2.33$ & $1.86,2.21$ & $1.79,2.13$ & $1.60,1.91$ & \\
\hline & CS & 1.69 & 0.78 & 0.82 & 0.84 & 0.82 & $>0.05$ \\
\hline & & I.57, I.82 & $0.7 I, 0.86$ & $0.74,0.90$ & $0.76,0.93$ & $0.75,0.91$ & \\
\hline
\end{tabular}


Table 5 Odds ratios for first hospitalization due to stroke

\begin{tabular}{|c|c|c|c|c|c|c|c|c|c|}
\hline & & & \multicolumn{2}{|l|}{ Univariate } & \multicolumn{5}{|l|}{ Multivariate } \\
\hline & & & $\begin{array}{l}\text { All } \\
\text { respiratory } \\
\text { drugs }\end{array}$ & $\begin{array}{l}\text { Plus } \\
\text { respiratory } \\
\text { comorbidity }\end{array}$ & $\begin{array}{l}\text { Plus } \\
\text { other } \\
\text { comorbidity }\end{array}$ & $\begin{array}{l}\text { Plus } \\
\text { cardiac } \\
\text { drugs }\end{array}$ & $\begin{array}{l}\text { Interaction } \\
\text { with cardiac } \\
\text { drugs } \\
\text { p-value }\end{array}$ & $\begin{array}{l}\text { No cardiac } \\
\text { drugs }\end{array}$ & $\begin{array}{l}\text { Cardiac } \\
\text { drugs }\end{array}$ \\
\hline \multirow[t]{6}{*}{60 Days } & IB & 1.18 & 1.20 & 1.09 & 1.10 & 1.04 & $<0.001$ & 1.46 & 0.96 \\
\hline & & $1.04,1.33$ & $1.03,1.40$ & $0.93,1.27$ & $0.94,1.28$ & $0.90,1.22$ & & $1.05,2.03$ & $0.81,1.14$ \\
\hline & BA & 1.08 & I.II & 1.05 & 1.05 & 1.01 & $<0.001$ & 1.32 & 0.94 \\
\hline & & $0.98,1.19$ & $0.98,1.26$ & $0.92,1.19$ & $0.92,1.19$ & $0.90,1.15$ & & $1.05,1.67$ & $0.8 \mathrm{I}, \mathrm{I} .08$ \\
\hline & CS & 0.90 & 0.79 & 0.78 & 0.80 & 0.78 & $>0.05$ & & \\
\hline & & $0.80,1.02$ & $0.68,0.91$ & $0.67,0.90$ & $0.69,0.92$ & $0.67,0.90$ & & & \\
\hline \multirow[t]{6}{*}{ I year } & IB & 1.30 & 1.32 & 1.20 & 1.18 & 1.13 & $<0.001$ & $\mathrm{I} .44$ & 1.06 \\
\hline & & I.I8, I.44 & I.I7, I.48 & I.07, I.36 & I.05, I.34 & $1.00,1.27$ & & I.II, I.87 & $0.93,1.21$ \\
\hline & BA & 1.13 & 1.12 & 1.08 & 1.06 & 1.01 & $<0.001$ & 1.31 & 0.95 \\
\hline & & $1.05,1.22$ & I.0I, I.24 & $0.97,1.19$ & $0.96,1.17$ & $0.92,1.12$ & & I.09, I.57 & $0.85,1.07$ \\
\hline & CS & 0.99 & 0.84 & 0.84 & 0.85 & 0.83 & $>0.05$ & & \\
\hline & & $0.90,1.08$ & $0.75,0.93$ & $0.75,0.94$ & $0.76,0.96$ & $0.74,0.94$ & & & \\
\hline
\end{tabular}

that cardiovascular events are common in COPD and that this relates to the degree of airways obstruction (Sin and Man 2003; Sin et al 2005). Arrhythmias have been documented as common in patients with severe COPD (Hudson et al 1973; Kleiger and Senior 1974), though it was likely these assessments were made in patients who were being treated with beta agonists. We cannot definitively refute the argument that bronchodilators were simply a marker of disease severity and this accounted for their association with cardiovascular disease, but we think it unlikely for two reasons. First, use of ICS was not associated with these outcomes.
ICS are recommended only in severe COPD as opposed to bronchodilators, recommended in all symptomatic cases. Cardiovascular risk was associated with bronchodilators, and not ICS, also markers of COPD severity. Further, the association of bronchodilators with cardiovascular outcomes was present in patients whose only diagnosis was bronchitis, a group with relatively few markers of disease severity such as physician visits and respiratory hospitalizations.

People who had cardiovascular events were more likely to be taking cardiac drugs than those who did not (Tables 1 and 2), as was expected. Of some surprise was

Table 6 Significant interactions between respiratory drugs and cardiac drug classes associated with causes of hospitalization*

\begin{tabular}{|c|c|c|c|c|c|c|c|}
\hline \multirow{2}{*}{$\begin{array}{l}\text { Respiratory drugs } \\
\text { Cardiac drugs }\end{array}$} & \multirow[t]{2}{*}{ Dispensed within } & \multicolumn{3}{|l|}{60 Days } & \multicolumn{3}{|l|}{365 Days } \\
\hline & & Off & On & p value & Off & On & $\mathrm{p}$ value \\
\hline \multirow[t]{4}{*}{$\overline{\text { SVT }}$} & IB and Antiarrhythmics & 1.76 & 0.72 & $<0.0001$ & 1.53 & 0.72 & $<0.0001$ \\
\hline & & $1.36,2.27$ & $0.52,0.99$ & & $1.24,1.89$ & $0.55,0.94$ & \\
\hline & BA and Antiarrhythmics & 1.32 & 0.77 & 0.0004 & 1.31 & 0.8 & 0.0001 \\
\hline & & $1.09,1.61$ & $0.60,1.00$ & & I.I2, I.52 & $0.65,0.99$ & \\
\hline \multirow[t]{2}{*}{ Myocardial infarction } & BA and Nitrates & & & & 1.26 & 1.00 & 0.012 \\
\hline & & & & & $1.13,1.41$ & $0.86,1.17$ & \\
\hline \multirow[t]{6}{*}{ Heart failure } & IB and Furosemide & $\mathrm{I} .75$ & 1.18 & 0.0002 & $\mathrm{I} .73$ & 1.26 & 0.0005 \\
\hline & & $1.45,2.10$ & $1.04,1.34$ & & $1.48,2.03$ & $1.13,1.40$ & \\
\hline & BA and Furosemide & 2.22 & $\mathrm{I} .45$ & $<0.0001$ & 1.68 & 1.28 & 0.0002 \\
\hline & & $1.94,2.54$ & $1.30,1.61$ & & $1.50,1.89$ & I.I7, I.4I & \\
\hline & $\mathrm{BA}$ and $\mathrm{ACEI}$ & 2.17 & 1.87 & 0.0417 & & & \\
\hline & & $1.94,2.43$ & $1.66,2.10$ & & & & \\
\hline \multirow[t]{4}{*}{ Stroke } & IB and ACEI & 1.26 & 0.88 & 0.006 & 1.33 & 1.01 & 0.01 \\
\hline & & $1.05,1.50$ & $0.70,1.09$ & & I.I5, I.54 & $0.86,1.20$ & \\
\hline & BA and Antihypertensives & 1.06 & 0.84 & 0.018 & 1.06 & 0.89 & 0.03 \\
\hline & & $0.93,1.21$ & $0.71,0.99$ & & $0.95,1.17$ & $0.78,1.01$ & \\
\hline
\end{tabular}

*Shown are odds ratios relating bronchodilators (IB or BA) to hospitalization for cardiovascular disease when patients were using (On) and not using (Off) groups of cardiac drugs. 
the finding that there were significant interactive effects between bronchodilators and cardiac drugs taken as a whole (Table 3); in all cases cardiac drugs decreased the likelihood of cardiovascular events associated with bronchodilators, especially IB. The example of stroke was especially striking; on the whole bronchodilators did not increase stroke risk after adjustment for confounders, but risk was apparently dependent upon precognition of cardiovascular disease, since it was increased in those on bronchodilators who were not taking cardiac drugs. Specific drug interactions supported this interpretation (Table 6); in each case the receipt of specific cardiac drugs decreased the likelihood of hospitalizations associated with bronchodilator. A particularly notable example of this kind of drug interaction was the fact that bronchodilators did not increase the risk of arrhythmia in the presence of anti-arrhythmic agents. Bronchodilators apparently impose a larger relative risk in people with unrecognized cardiovascular disease than in people with known disorders.

As noted above, ICS were not associated with cardiovascular events. Indeed, they appeared to be protective, an effect that was occasionally significant. We have previously shown in a similar cohort that ICS were associated with reduced cardiovascular mortality as compared to patients taking bronchodilators in the absence of ICS (Macie et al 2006). It is possible that the beneficial effect of ICS is dependent upon reduction of cardiovascular events associated with bronchodilator therapy, since ICS are seldom used in the absence of bronchodilators.

\section{References}

Anthonisen NR, Connett JE, Enright PL, et al. 2002. Hospitalizations and mortality in the Lung Health Study. Am J Respir Crit Care Med, $166: 333-9$.

Au DH, Curtis JR, Every NR, et al. 2002. Association between inhaled $\beta$-agonists and the risk of unstable angina and myocardial infarction. Chest, 121:846-51.

Au DH, Udris EM, Fan VS, et al. 2003. Risk of mortality and patients with known left ventricular systolic dysfunction. Chest, 123:1964-9.

Au DH, Udris EM, Curtis JR, et al. 2004. Association between chronic heart failure and inhaled $\beta-2$ adrenoceptor agonists. Am Heart J, 148:915-20.

Coleman AJ, Leary UP, Kaul DS. 1975. Hemodynamic effects of Sch 1000 in normal subjects. Postgrad Med J, 51(Suppl 7):121.
Coughlin SS, Metayer C, McCarthy EP, et al. 1995. Respiratory illness, $\beta$-agonists and risk of idiopathic dilated cardiomyopathy. Am J Epidemiol, 142:395-403.

Curkendall SM, DeLuise C, Jones JK, et al. 2006. Cardiovascular disease in patients with chronic obstructive lung disease, Saskatchewan Canada. Ann Epidemiol, 16:63-70.

Guite HF, Dundas R, Burney PGJ. 1999. Risk factors for death from asthma, chronic obstructive pulmonary disease, and cardiovascular disease after a hospital admission for asthma. Thorax, 54:301-7.

Hudson LD, Kurt TL, Petty TL, et al. 1973. Arrhythmias associated with acute respiratory failure in patients with chronic airway obstruction. Chest, 63:661-5.

Huzel L, Roos LL, Anthonisen NR, et al. 2002. Diagnosing asthma: the fit between survey and administrative database. Canad Respir J, 9:407-12.

Iskandar SB, Mathai MG, Byrd RP, et al. 2004. Myocardial injury during standard treatment of an adult with status asthmaticus. J Asthma, 41:337-42.

Kallergis EM, Manios EG, Kanoupakis EM, et al. 2005. Acute electrophysiologic effects of inhaled salbutamol in humans. Chest, 127:2057-63.

Kleiger RE, Senior RM. 1974. Long term electrocardiographic monitoring of ambulatory patients with chronic airway obstruction. Chest, 65:483-7.

Macie C, Wooldrage K, Manfreda J, et al. 2006. Inhaled corticosteroids and mortality in COPD. Chest, 130:640-6.

Ringbaek T, Viskum K. 2003. Is there any association between inhaled ipratropium and mortality in patients with COPD and asthma? Resp Med, 97:264-72.

Robin ED, McCauley R. 1992. Sudden cardiac death in bronchial asthma, and inhaled beta-adrenergic agonists. Chest, 101:1699-702.

Salpeter SR, Ormiston TM, Salpeter EE. 2004. Cardiovascular effects of $\beta$-agonists in patients with asthma and COPD. A meta-analysis. Chest, 125:2309-21.

Sin DD, Tu JV. 2000. Lack of association between ipratropium bromide and mortality in elderly patients with chronic obstructive airway disease. Thorax, 55:194-7.

Sin DD, Mann SFP. 2003. Why are patients with chronic obstructive pulmonary disease at increased risk of cardiovascular diseases? Circulation, 107:1514-9.

Sin DD, Wu L, Mann SFP. 2005. The relationship between reduced lung function and cardiovascular mortality. A population-based study and a systematic review of the literature. Chest, 127:1952-9.

Suissa S, Ernst P, Boivin JF, et al. 1994. A cohort analysis of excess mortality in asthma and the use of inhaled $\beta$-agonists. Am J Respir Crit Care Med, 149:604-10.

Suissa S, Hemmelgarn B, Blais L, et al. 1996. Bronchodilators and acute cardiac death. Am J Respir Crit Care Med, 154:1598-602.

Suissa S, Assimes T, Ernst P. 2003. Inhaled short acting $\beta$-agonist use in COPD and the risk of acute myocardial infarction. Thorax, 58:43-6.

[WHO] World Health Organisation. 1978. International classification of diseases, 9th revision. Geneva: WHO.

[WHO] World Health Organization. 1995. World Health Organization's Centre for Drug Statistics Methodology: Guidelines for ATC classification and DDD assignment. Oslo, Norway: WHO. 
